Analytical Methods

\title{
Real time monitoring of alcoholic fermentation with low-cost amperometric biosensors
}

\author{
S. Piermarini ${ }^{\text {a,* }}$, G. Volpe ${ }^{\text {a }}$, M. Esti ${ }^{\text {b }}$, M. Simonetti ${ }^{\text {a }}$, G. Palleschi ${ }^{\text {a }}$ \\ ${ }^{a}$ Dipartimento di Scienze e Tecnologie Chimiche, Università di Roma Tor Vergata, Via della Ricerca Scientifica, 00133 Rome, Italy \\ bipartimento di Scienze e Tecnologie Alimentari, Università della Tuscia, via S. Camillo de Lellis, 01100 Viterbo, Italy
}

\section{A R T I C L E I N F O}

\section{Article history:}

Received 19 April 2010

Received in revised form 13 October 2010

Accepted 1 January 2011

Available online 8 January 2011

\section{Keywords:}

Screen-printed biosensors

Micro-alcoholic fermentation

Glucose

Fructose

Ethanol

Red winemaking

\begin{abstract}
A B S T R A C T
Screen-printed glucose, ethanol and fructose biosensors, coupled with portable instrumentation, and their application to monitor micro-alcoholic fermentations (micro-ALFs) in red wine is described. For the fabrication of glucose and ethanol biosensors, graphite screen-printed sensors modified with Prussian Blue were coupled with oxidase enzymes while for the fructose biosensor, a bare screen-printed sensor was coated with fructose dehydrogenase and phenazine methansulphate was used as electrochemical mediator. The working range, reproducibility of probe fabrication and biosensor stability were all evaluated. After a recovery study, performed analysing fortified must-wine samples, the biosensors were employed to monitor micro-ALFs induced by the inoculation of two different strains of Saccharomyces cerevisiae. During the red micro-ALFs, samples of must-wine were collected and analysed by use of both biosensors and spectrophotometric kits. The data obtained demonstrated that a biosensor-based system could represent a useful tool to assist winemakers during wine production.
\end{abstract}

(c) 2011 Elsevier Ltd. All rights reserved.

\section{Introduction}

Alcoholic fermentation is a crucial step in the production of wine, resulting in the transformation of sugars (glucose and fructose) by yeast (Saccharomyces cerevisiae) into alcohol and carbon dioxide. A not uncommon experience for winemakers is a slow and/or incomplete consumption of sugars by yeast during alcoholic fermentation. A stuck fermentation can be caused by various factors, including nutrient limitation, temperature, $\mathrm{pH}$ variation, lack of oxygen, presence of toxic compounds and poor ethanol tolerance of the yeast strain (Bisson, 1999; Santos et al., 2008). It is known that the kinetics of sugar consumption by yeast are strongly influenced by transport rate within the cell: hexose transporters, for example, possess greater affinity for glucose than fructose, which explains why, in a stuck fermentation, the residue sugar is mainly fructose (Berthels et al., 2004, 2008). If the stuck fermentation is an adaptive response of the yeast to adverse conditions, the readjustment of the medium must occurs prior to commitment to that adaption (Bisson \& Butzke, 2000). Thus, it is desirable to supply winemakers with new analytical methods that are simple, rapid and of low cost, so that it becomes possible to monitor the alcoholic fermentation and detect the occurrence of anomalous profiles. Biosensor technology has great potential for this purpose. In this area, Niculescu, Mieliauskiene, Laurinavicius, and Csöregi

\footnotetext{
* Corresponding author. Tel.: +39 06 72594420; fax: +39 0672594328.

E-mail address: silvia.piermarini@uniroma2.it (S. Piermarini).
}

(2003) have proposed dehydrogenase-based biosensors for on-line detection of ethanol, glucose and glycerol in wines. However, the construction of these devices was very laborious, requiring the isolation and purification of $\mathrm{PQQ}$-dependent dehydrogenase and also the synthesis of the electrochemical mediator ( $\left.\mathrm{PVI}_{13} \mathrm{dmeOs}\right)$.

Our research group has already developed conventional amperometric biosensors that were inserted into a flow injection analysis (FIA) systems for the detection of glucose, fructose and ethanol (Esti et al., 2003). Although the effectiveness of these systems has been demonstrated for real-time monitoring of alcoholic fermentation in industrial-scale red winemaking, the overall system was somewhat cumbersome to use. More recently, to overcome these drawbacks, Goriushkina, Soldatkin, and Dzyadevych (2009) have developed amperometric biosensors for a more convenient detection of glucose and ethanol in wine. These biosensors are based on the use of specific enzymes, such as alcohol and glucose oxidase (AO and GOD), immobilized onto the surface of bare platinum printed electrodes. The $\mathrm{H}_{2} \mathrm{O}_{2}$, produced by enzymatic reactions, was measured at $+200 \mathrm{mV} v s$. $\mathrm{Ag} / \mathrm{AgCl}$; this working potential was chosen as a compromise between high biosensor sensitivity and low current signal due to electrochemical interferences. Other biosensors for the detection of ethanol in wine and beer were developed (Boujtita, Hart, \& Pittson, 2000; Patel, Meier, Cammann, \& Chemnitius, 2001) using platinum or carbon (doped with cobalt phthalocyanine) screen-printed electrodes and alcohol oxidase. In both cases, the $\mathrm{H}_{2} \mathrm{O}_{2}$, produced by the enzymatic reactions, was measured at high applied potentials and for this reason 
it was necessary to adopt different strategies to eliminate electrochemical interferences.

Recently, a low cost, portable and disposable fructose biosensor has been developed using FDH immobilised in a polymer matrix of polyethyleneimine and poly(carbamoylsulphonate) hydrogel. Because a ferricyanide mediator was used as electron acceptor, the applied potential was quite high $(+400 \mathrm{mV})$. Moreover, this biosensor was not tested for the detection of fructose in must and wine samples (Trivedi, Lakshminarayana, Kothari, Patel, \& Panchal, 2009).

The work reported here is aimed specifically at the development of screen-printed biosensors incorporated into a system applicable for the practical monitoring of alcoholic fermentation. Because glucose and fructose are the sugars consumed by yeast during grape must fermentation, and in a stuck fermentation the residual sugar is mainly fructose, here we have developed screen-printed biosensors for the detection of both sugars as well as ethanol.

For the fabrication of the GOD and AO biosensors, we used graphite screen-printed sensors modified with Prussian Blue (PB). The use of this electrochemical mediator, deposited on the surface of the working electrode, allows a very sensitive and selective detection of $\mathrm{H}_{2} \mathrm{O}_{2}$, at a low applied potential $(-50 \mathrm{mV})$. Instead, for detection of fructose, the enzyme fructose dehydrogenase (FDH) was immobilized on the surface of bare graphite SPE and the mediator phenazine methansulphate (PMS) was used as enzymatic co-substrate. The reduced form of PMS was measured at a low applied potential of $+70 \mathrm{mV} v s$. $\mathrm{Ag} / \mathrm{AgCl}$ pseudoreference electrode.

The optimised biosensors were finally employed to monitor micro-alcoholic fermentations that were carried out in our laboratory, induced by the inoculation of two different strains of S. cerevisiae into separate batches of must. The progress of the micro-ALFs was monitored by following the degradation of glucose and fructose, and the production of ethanol.

\section{Materials and methods}

\subsection{Reagents and materials}

D-glucose, D-fructose, ethyl alcohol, sucrose, lactitol, DEAE-dextran, phenazine methansulphate (PMS), glycine, Nafion ${ }^{\circledR}$, glutaraldehyde, bovine serum albumin (BSA), glucose oxidase (GOD) from Aspergillus niger type VII (197 U/mg), alcohol oxidase (AO) from Pichia pastoris $(1350 \mathrm{U} / \mathrm{mL})$, and $\mathrm{D}$-fructose dehydrogenase (FDH) from Gluconobacter industrius ( $90 \mathrm{U} / \mathrm{mg}$ ) were obtained from Sigma (St. Louis, MO, USA). All other reagents of analytical grade were from Carlo Erba (Milano, Italy).

Spectrophotometric kits for ethanol and D-glucose/D-fructose were from R-Biopharm (Darmstadt, Germany).

\subsection{Buffer solutions}

The buffer solutions used in this work are the following: $0.05 \mathrm{M}$ phosphate buffer, pH 7.0 (TPi); $0.05 \mathrm{M}$ phosphate buffer, $\mathrm{pH}$ $7.4+0.1 \mathrm{M} \mathrm{KCl}(\mathrm{TPi}+\mathrm{KCl}) ; 0.05 \mathrm{M}$ citrate phosphate buffer, $\mathrm{pH}$ 4.5 (TCPi); $0.05 \mathrm{M}$ citrate phosphate buffer, $\mathrm{pH} 4.5+0.1 \mathrm{M} \mathrm{KCl}$ $(\mathrm{TCPi}+\mathrm{KCl})$.

\subsection{Apparatus and electrodes}

Cyclic voltammetry (CV) and chronoamperometry measurements were performed using a PalmSens electrochemical detector equipped with PSLite software (Palm Instruments BV, The Netherlands).
Screen-printed electrodes (SPEs) were home produced with a DEK (Weymouth, UK) screen-printing machine. Graphite-based ink (Elettrodag 421), silver ink (Electrodag 477 SS RFU) and insulating ink (Electrodag 6018 SS) were obtained from Acheson (Milan, Italy). The substrate was a polyester flexible film (Autostat HT5) from Autotype Italia (Milan, Italy). The printing procedure utilised has already been described (Cagnini, Palchetti, Lionti, Mascini, \& Turner, 1995). The electrodes were produced in foils of 20 strips and the diameter of the working electrode was $0.3 \mathrm{~cm}$, which resulted in an apparent geometric area of $0.07 \mathrm{~cm}^{2}$.

\subsection{Procedures}

\subsubsection{Electrode pretreatment}

The SPEs were pre-treated in $\mathrm{TPi}+\mathrm{KCl}$, by applying an anodic potential of $1.7 \mathrm{~V}$ for $180 \mathrm{~s}$. They were then stored dry at room temperature (RT) in the dark prior to use (Ricci, Amine, Palleschi, \& Moscone, 2003).

\subsubsection{Preparation of PB-modified SPEs}

According to the procedure of Ricci et al. (2003), PB modification of SPEs was accomplished by placing a drop ( $20 \mu \mathrm{l}$ total volume) of 'precursor solution' onto the working electrode. This solution is obtained by mixing $10 \mu \mathrm{l}$ of $0.1 \mathrm{M} \mathrm{K} \mathrm{K}_{3} \mathrm{Fe}(\mathrm{CN})_{6}$ with $10 \mu \mathrm{l}$ of $0.1 \mathrm{M} \mathrm{FeCl}_{3}$ (both prepared in $10 \mathrm{mM} \mathrm{HCl}$ ). The drop solution was left on the electrode surface for $10 \mathrm{~min}$ and then rinsed with a few milliliters of $10 \mathrm{mM} \mathrm{HCl}$. The electrodes were then left $90 \mathrm{~min}$ in the oven at $100{ }^{\circ} \mathrm{C}$ to obtain a more stable and active layer of PB. Once deposited, the functionality of PB layer was tested by cyclic voltammetry in a potential range between -0.2 and $+0.5 \mathrm{~V}$, with a scan rate of $50 \mathrm{mV} \mathrm{s}^{-1}$ in $\mathrm{TPi}+\mathrm{KCl}$.

The PB-modified electrodes were then stored dry at RT in the dark.

\subsubsection{Cyclic voltammetry of PMS}

In order to evaluate the electrochemical profile of PMS on the graphite SPE, $100 \mu \mathrm{L}$ of $3 \mathrm{mM}$ PMS solution (prepared in TCPi $+\mathrm{KCl}$ and protected from light) was added to cover the three-electrode system and cyclic voltammetry measurements were carried out in the potential range between +0.3 and $-0.4 \mathrm{~V}$ with a scan rate of $50 \mathrm{mV} \mathrm{s}^{-1}$.

\subsubsection{Enzyme immobilization}

GOD was immobilized onto SPE modified with PB using a procedure optimized by (Ricci et al., 2005): $3 \mu \mathrm{L}$ of glutaraldhehyde ( $1 \%$ $\mathrm{v} / \mathrm{v}$ diluted in water) was pipetted onto the working electrode surface and dried for $20 \mathrm{~min}$. After the addition of $3 \mu \mathrm{L}$ of the mixture, obtained by mixing $100 \mu \mathrm{L}$ of $2 \%$ Nafion $^{\circledR}(\mathrm{v} / \mathrm{v}$ in water) and $100 \mu \mathrm{L}$ of GOD $(10 \mathrm{mg} / \mathrm{mL}$ in TPi), onto the working electrode area, the solution was allowed to dry for $20 \mathrm{~min}$ at RT. The SPE-PB-GOD biosensors were then stored dry at $4{ }^{\circ} \mathrm{C}$ in the dark.

AO immobilization onto SPE-PB was performed as follows: $25 \mu \mathrm{L}$ of the commercial AO solution supplemented with $4 \%$ BSA $(\mathrm{w} / \mathrm{v})$ was mixed, in a porcelain well using a glassy stick, with $8 \mu \mathrm{L}$ of $5 \%$ Nafion $^{\circledR}$ and $5 \mu \mathrm{L}$ of $2.5 \%$ glutaraldhehyde $(\mathrm{v} / \mathrm{v}$ in TPi). Five microlitre of the resulting mixture was pipetted onto the working electrode and allowed to dry for $1 \mathrm{~h}$. In order to block the unreacted functional groups of glutaraldhehyde, the AO biosensor was washed in $0.1 \mathrm{M}$ glycine for $30 \mathrm{~min}$. The SPE-PB-AO biosensors were stored at $4{ }^{\circ} \mathrm{C}$ in TPi, containing sucrose $(30 \% \mathrm{w} / \mathrm{v})$.

The FDH enzyme immobilisation procedure was the following: $4 \mu \mathrm{l}$ of the commercial enzymatic solution was mixed with $5 \mu \mathrm{l}$ BSA $(10 \mathrm{mg} / \mathrm{ml}$ in $\mathrm{TPi})$ and $1 \mu \mathrm{l}$ of $0.25 \%$ glutaraldehyde $(\mathrm{v} / \mathrm{v}$ in TPi) in a porcelain well using a glassy stick. Then, $4 \mu \mathrm{l}$ of the mixture was pipetted on the working electrode and dried for $30 \mathrm{~min}$. 
The SPE-FDH biosensor, when not in use, was stored at $4{ }^{\circ} \mathrm{C}$ in TCPi containing DEAE-dextran ( $1 \% \mathrm{w} / \mathrm{v})$ and lactitol $(5 \% \mathrm{w} / \mathrm{v})$.

\subsubsection{Preparation of standard solutions}

Standard solutions $0.02-0.7 \mathrm{mM}$ for glucose and $0.05-0.5 \mathrm{mM}$ for ethanol were prepared, daily, in $\mathrm{TPi}+\mathrm{KCl}$.

Fructose standard solutions $0.05-0.5 \mathrm{mM}$ were prepared, daily, in $\mathrm{TCPi}+\mathrm{KCl}+3 \mathrm{mM}$ PMS. These solutions were protected from light.

\subsubsection{Biosensor analysis schemes}

The biosensors for the analysis of glucose, fructose and ethanol are based on the following enzymatic reactions:

Glucose $+\mathrm{O}_{2}-\mathrm{GOD} \rightarrow$ gluconic acid $+\mathrm{H}_{2} \mathrm{O}_{2}$

Alcohol $+\mathrm{O}_{2}-\mathrm{AO} \rightarrow$ aldehyde $+\mathrm{H}_{2} \mathrm{O}_{2}$

The $\mathrm{H}_{2} \mathrm{O}_{2}$ produced, in both cases, reacts with the reduced form of $\mathrm{PB}$ as follows:

$$
\mathrm{H}_{2} \mathrm{O}_{2}+\mathrm{PB}_{\text {red }} \rightarrow 2 \mathrm{OH}^{-}+\mathrm{PB}_{\mathrm{ox}}
$$

The current generated by the reduction of $\mathrm{PB}_{\mathrm{ox}}$, at the working electrode polarised at $-50 \mathrm{mV}$ ( $v s$. Ag pseudoreference electrode), was directly proportional to the glucose or ethanol concentration.

Fructose $+2 \mathrm{PMS}^{+}-\mathrm{FDH} \rightarrow$ ketofructose $+2 \mathrm{PMSH}$

The FDH reaction produces the reduced form of phenazine methansulphate, which was oxidised at the working electrode polarised at $+70 \mathrm{mV}$ ( $v s$. Ag pseudoreference electrode).

Prior to the electrochemical measurements, the biosensors were washed three times with a drop of buffer ( $\mathrm{TPi}+\mathrm{KCl}$ for glucose and ethanol, TCPi $+\mathrm{KCl}$ for fructose) and then connected to the PalmSens instrument. After that, $100 \mu$ of a suitable buffer was added to the SPE to cover the three-electrode system and chronoamperometric measurements were carried out for $30 \mathrm{~s}$. The measured current (baseline) was subtracted from the one generated by measuring standard solutions or must/wine samples, under the same experimental conditions.

\subsubsection{Micro-ALFs}

The optimised biosensors were employed to monitor microALFs performed in our laboratory using Cabernet Sauvignon grapes $(26 \pm 2$ Brix, pH 3.8, total acidity $3.9 \mathrm{~g} / \mathrm{L}$ ) obtained from Antinori Sovana winery (in the Tuscan region). The fermentation process was initiated by inoculating must with two selected commercial strains of S. cerevisiae: Uvaferm 43 YSEO and Lalvin 71B (Lalle- mand, Toulouse, France). As reported in the technical leaflets, the former (named strain F) is known for its fructophilic character (it is normally used to restart stuck fermentations) and for high resistance to ethanol $(>17 \% \mathrm{v} / \mathrm{v}$ ), the latter (named strain NF) for its high fermenting force and high affinity for glucose.

The scheme used for the micro-ALFs procedure is summarised in Fig. 1. The must, resulting from grape crushing/destemming, was divided in two batches. After rehydratation of each lyophilised strain and cell pre-multiplication, the obtained suspensions (NF and $\mathrm{F}$ strains) were inoculated into the two batches, sulphited in advance.

The micro-ALFs were carried out in 5 L glass flasks, covered with perforated parafilm (to allow oxygenation), and kept at $20^{\circ} \mathrm{C}$ for the first $24 \mathrm{~h}$ and then maintained at $26^{\circ} \mathrm{C}$. At different intervals, the pomace cap was repeatedly sunk (using a special shaft equipped with a perforated disc, which allows both the aeration and mixing of the mass) and $1 \mathrm{~mL}$ aliquots of must-wine samples were collected.

\section{Results and discussion}

\subsection{Electrochemical study of PMS}

The electrochemical behaviour of PMS on SPEs was evaluated by cyclic voltammetry (Section 2.4 .3 ). These experiments were carried out while protecting the working solution of PMS from the light during the CV experiments and, under these conditions, no decrease of current peaks was observed even after 100 cycles (data not shown). This demonstrates that no fouling of the electrode surface occurs with PMS solution, as previously reported by Curulli, Carelli, Trischitta, and Palleschi (1997).

Moreover, this study allowed the determination of the optimal potential $(+70 \mathrm{mV})$ for chronoamperometric measurements (Section 2.4.6).

\subsection{Evaluation of biosensor performance}

After optimisation of the enzyme immobilisations onto the surface of both PB-SPEs and bare SPEs, calibration curves for glucose, fructose and ethanol were generated. The biosensors developed showed linear responses to glucose, fructose and ethanol within the concentration range $0.02-0.7 \mathrm{mM}, 0.05-0.5 \mathrm{mM}$ and $0.05-$ $0.5 \mathrm{mM}$, respectively. The reproducibility of the biosensor fabrication was evaluated by testing standard solutions of analytes (at three concentration levels) with four GOD, AO and FDH biosensors prepared either on the same day (intra-day) or on different days

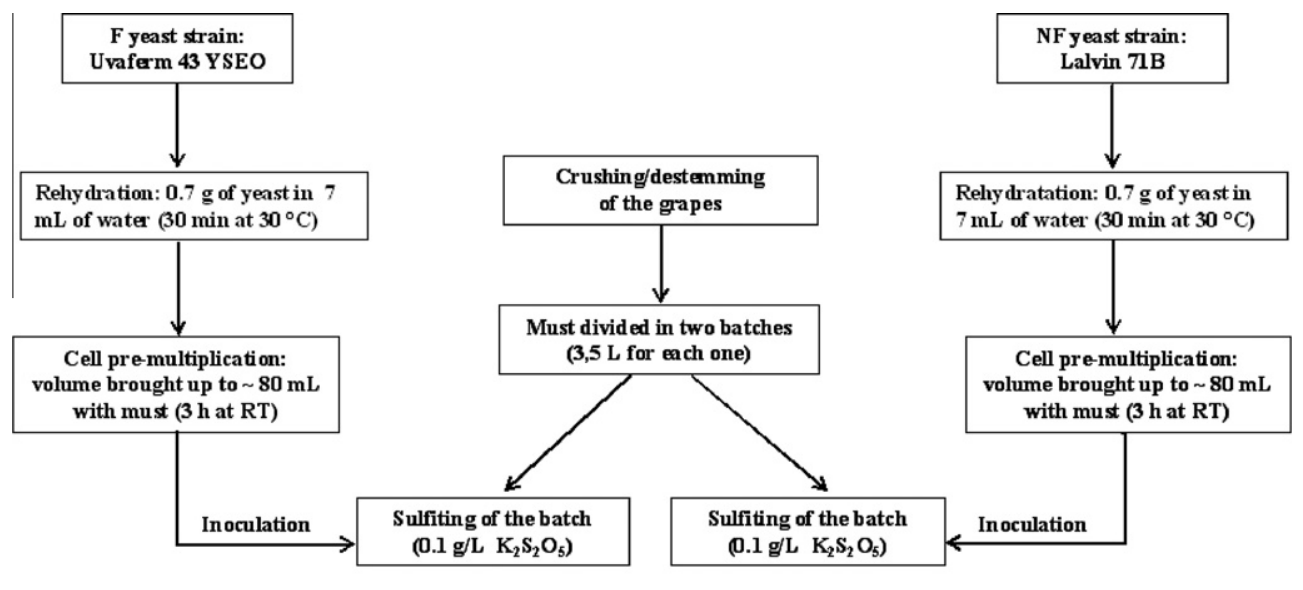

Fig. 1. Procedure used for the micro-ALFs. 
(inter-day). The results (not shown) demonstrated good reproducibility in the fabrication of such devices. Indeed, for all biosensors, we obtained average values of precion (RSD) equal to $5 \%$ (intraday) and 7\% (inter-day).

\subsection{Study of biosensor stability}

The stability study of GOD, AO and FDH biosensors was carried out by analysing standard solutions of the respective analytes at different intervals after the biosensor preparation. The data showed that about $90 \%$ of initial activity remained for 6 months (GOD biosensor), one month (AO biosensor) and 15 days (FDH biosensor) of storage, under the conditions reported in the Section
2.4.4; subsequently there was a gradual decrease. Furthermore, each biosensor, although considered as a disposable device, can be used to analyse at least 100 (GOD biosensor), 50 (AO biosensor) and 30 (FDH biosensor) samples of must and wine, without loss of activity.

\subsection{Recovery study}

Recovery studies to evaluate the matrix effect (must and red wine) on the biosensor performance were carried out by the addition of different amounts of standard solutions of the analytes to the samples to be tested. In particular, standard solutions of ethanol were added to a must with non-detectable ethanol content,

\section{Table 1}

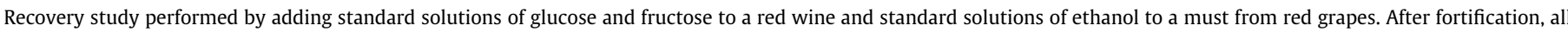
samples were diluted 1:200 and tested with the biosensors.

\begin{tabular}{|c|c|c|c|c|}
\hline Glucose found before spiking (mM) & Glucose added (mM) & Total glucose expected (mM) & Total glucose found \pm s.d. $(\mathrm{mM})$ & Recovery $^{*}(\%)$ \\
\hline n.d. & 4.0 & 4.0 & $3.8 \pm 0.2$ & $95 \pm 5$ \\
\hline n.d. & 10.0 & 10.0 & $9.8 \pm 0.5$ & $98 \pm 5$ \\
\hline n.d. & 20.0 & 20.0 & $20.0 \pm 0.6$ & $100 \pm 3$ \\
\hline n.d. & 100 & 100 & $102 \pm 2$ & $102 \pm 2$ \\
\hline n.d. & 140 & 140 & $147 \pm 3$ & $105 \pm 2$ \\
\hline Ethanol found before spiking (mM) & Ethanol added (mM) & Total ethanol expected (mM) & Total ethanol found \pm s.d. $(\mathrm{mM})$ & Recovery ${ }^{*}(\%)$ \\
\hline n.d. & 10.0 & 10.0 & $9.8 \pm 0.3$ & $100 \pm 3$ \\
\hline n.d. & 20.0 & 20.0 & $19.0 \pm 0.4$ & $95 \pm 2$ \\
\hline n.d. & 40 & 40 & $40 \pm 1$ & $100 \pm 3$ \\
\hline n.d. & 100 & 100 & $98 \pm 2$ & $98 \pm 2$ \\
\hline Fructose found before spiking (mM) & Fructose added (mM) & Total fructose expected (mM) & Total fructose found \pm s.d. $(\mathrm{mM})$ & Recovery $^{*}(\%)$ \\
\hline 24 & 10 & 34 & $34 \pm 1$ & $100 \pm 3$ \\
\hline 24 & 20 & 44 & $42 \pm 1$ & $95 \pm 2$ \\
\hline 24 & 40 & 64 & $64 \pm 1$ & $100 \pm 2$ \\
\hline
\end{tabular}

n.d. = not detectable.

* Each value is the mean of three determinations.

a

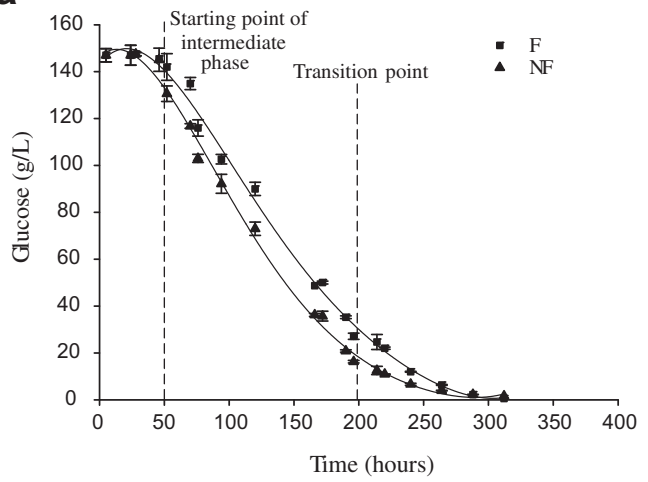

b

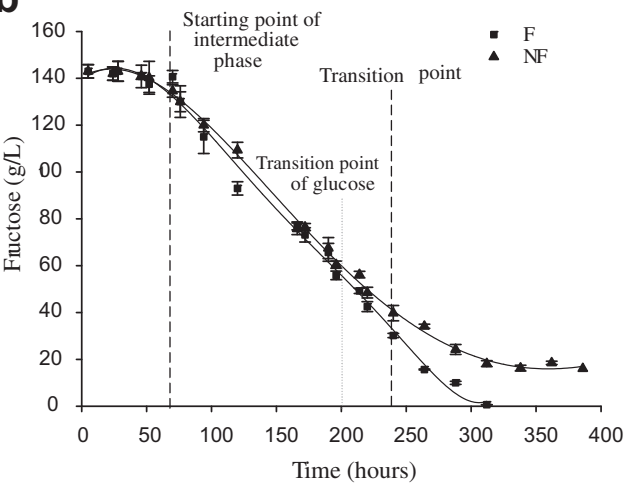

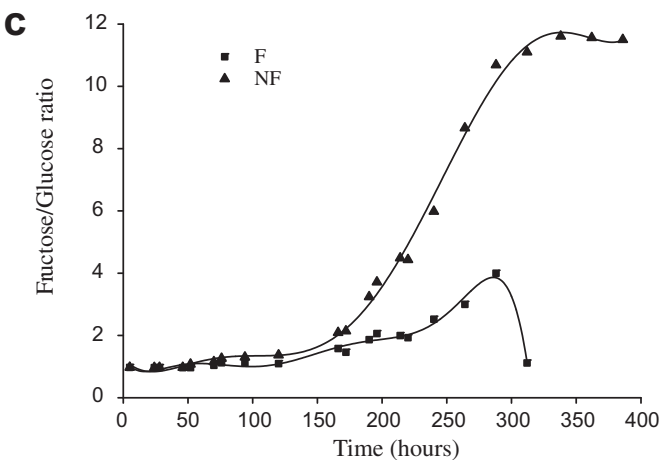

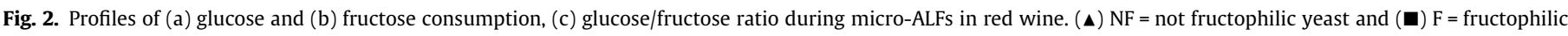
yeast. 
while standard solutions of glucose and fructose were added to a wine, with an amount of glucose not detectable by GOD biosensor, but containing a fructose concentration of $24 \mathrm{mM}$ (quantified by FDH biosensor and confirmed by spectrophotometric kit). Recovery and precision are reported in Table 1 . Since samples must be diluted at least 1:200 in the appropriate buffer (in order to avoid electrochemical interferences), this dilution was tested for recovery. The fortified levels were chosen so that they do not exceed the maximum limit of linearity of the developed biosensor devices. Further dilutions of the samples were performed for higher analyte concentrations. In all cases, a recovery from $95 \%$ to $105 \%$ and a precision of $<5 \%$ were obtained.

\subsection{ALFs monitoring at laboratory-scale}

After mass mixing (repeated sinking of grape skins into the juice), must-wine samples were collected for biosensor analysis of glucose, fructose and ethanol.

In all experimental trials, the kinetics observed for the three analytes were clearly divided into three characteristic phases: early, with no detectable variations of the analytes because the yeast must adapt its metabolism to the new growth medium; intermediate, characterised by rapid sugar consumption; and late, with little variation of sugar concentration (Fig. 2a, b). Between the intermediate and late phases it is possible to identify a transition point.

The duration of the early phase characterised by negligible sugar consumption was quite long and differed for glucose and fructose. Indeed, for both batches, the yeast needed about $50 \mathrm{~h}$ (Fig. 2a) and $76 \mathrm{~h}$ (Fig. 2b) to begin the breakdown of glucose and fructose, respectively. The yeast adaptation to the medium was probably made difficult by the high sugar concentration and low initial temperature selected $\left(20^{\circ} \mathrm{C}\right)$.

The monitoring of the intermediate phase allowed for the differentiation of the consumption profile of glucose and fructose by the two yeast strains ( $\mathrm{F}$ and NF). As to the uptake of glucose (Fig. 2a), NF yeast showed a greater fermentation force than $F$ yeast, with an average consumption rate (up until the transition point) of 0.86 and $0.76 \mathrm{~g} \mathrm{~L}^{-1} \mathrm{~h}^{-1}$, respectively. This different behaviour implies that, at the transition point $(\sim 200 \mathrm{~h})$ the residual concentration of glucose in the medium is higher for the $\mathrm{F}\left(\sim 40 \mathrm{~g} \mathrm{~L}^{-1}\right)$ than the NF batch $\left(\sim 20 \mathrm{~g} \mathrm{~L}^{-1}\right)$.

On the contrary, in the late phase (after $200 \mathrm{~h}$ ) it was observed that for $\mathrm{F}$ strain there was an average consumption rate of glucose

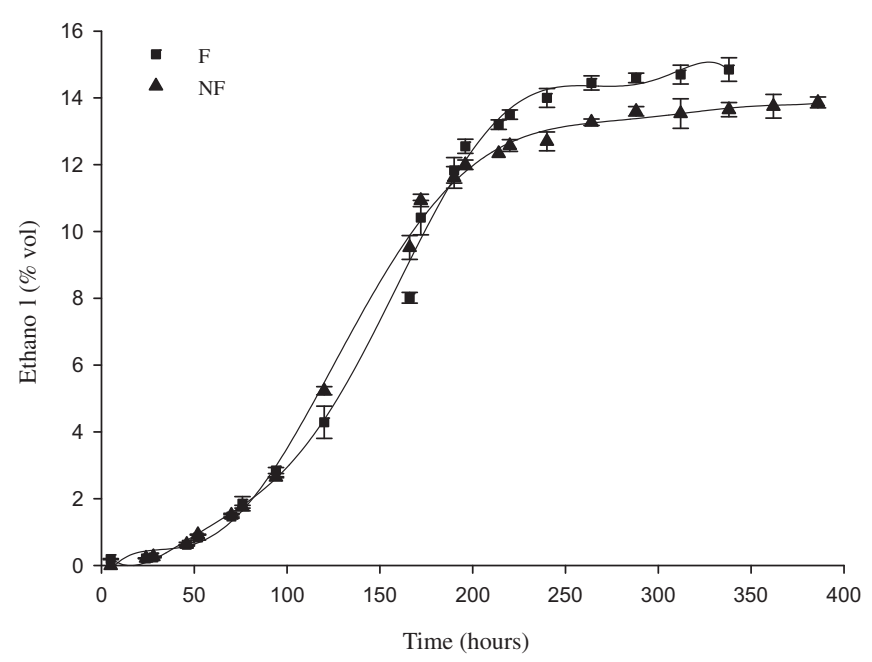

Fig. 3. Profiles of ethanol production during micro-ALFs in red wine. $(\boldsymbol{\Delta}) \mathrm{NF}=$ not fructophilic yeast and $(\mathbf{a}) \mathrm{F}=$ fructophilic yeast. $\left(0.28 \mathrm{~g} \mathrm{~L}^{-1} \mathrm{~h}^{-1}\right)$ twice that of NF strain $\left(0.15 \mathrm{~g} \mathrm{~L}^{-1} \mathrm{~h}^{-1}\right)$. This can be ascribed to the high ethanol resistance of $F$ strain, which guaran-
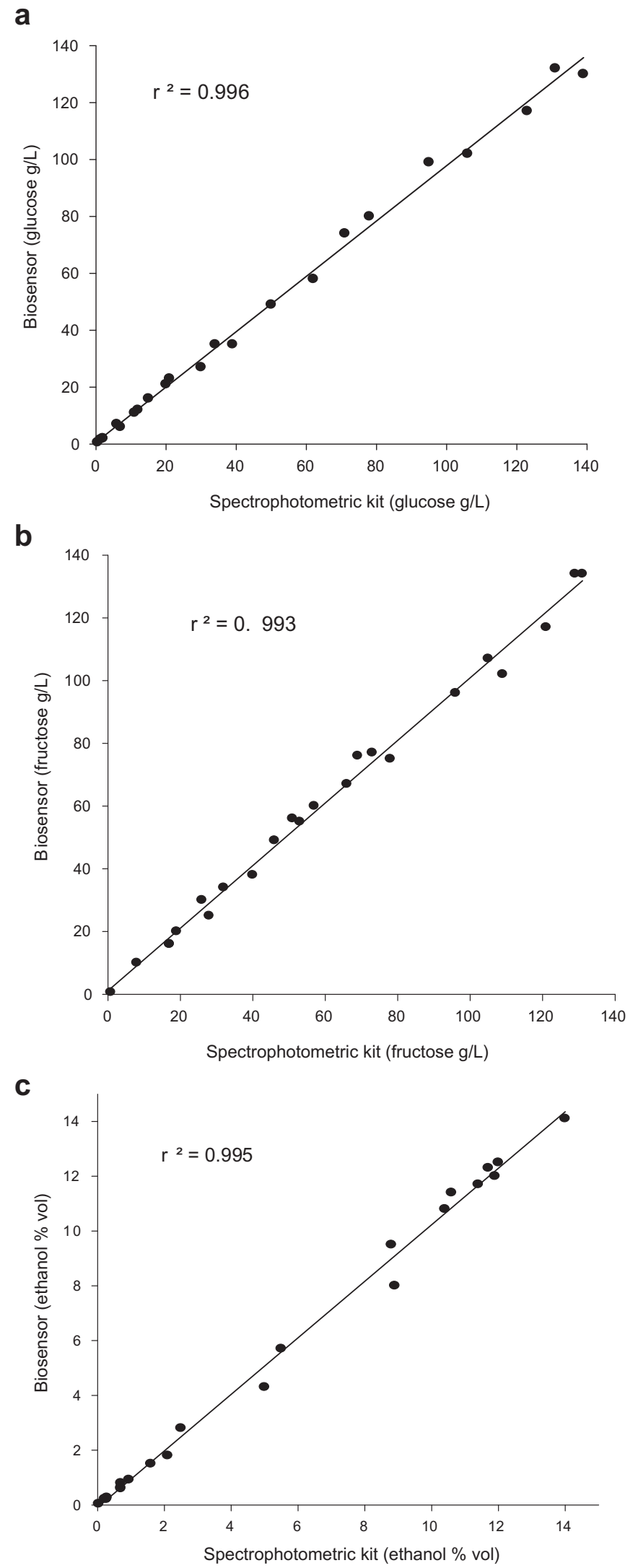

Fig. 4. Correlation between (a) glucose, (b) fructose and (c) ethanol values measured by biosensors and spectrophotometric kits during micro-ALFs. 
tees a better breakdown of sugars in stressing conditions (etha$\mathrm{nol}>12 \% \mathrm{v} / \mathrm{v}$ ).

Similarly, we can describe the differential behaviour of the two strains with respect to the fructose consumption. As reported in Fig. $2 b$, one can see that the intermediate phase is characterised by a greater fermentation force of $\mathrm{F}$ relative to NF strain, with an average consumption rate (until the transition point $\sim 240 \mathrm{~h}$ ) of fructose equal to $0.61 \mathrm{~g} \mathrm{~L}^{-1} \mathrm{~h}^{-1}$ and $0.51 \mathrm{~g} \mathrm{~L}^{-1} \mathrm{~h}^{-1}$, respectively. It is worth to note that after $200 \mathrm{~h}$ (transition point for glucose), the decreased availability of glucose leads the yeasts, in both batches, to preferentially consume fructose relative to glucose. In particular, the greater affinity of the F strain for fructose, allowing a more rapid consumption of this hexose than by the NF strain, resulted in a clear separation of the two profiles. Indeed, it can be seen that only the F strain was able to completely consume the fructose while NF strain had difficulty in completing the degradation of the last grams of fructose $\left(\sim 16 \mathrm{~g} \mathrm{~L}^{-1}\right)$.

The fructose/glucose ratio $(F / G)$ can be used as a useful index to reflect the occurrence of either a normal or an anomalous fermentation profile. Generally, for a complete alcoholic fermentation, this ratio starts from a value of about 1 , reaches a maximum (varying between 3 and 8 ) and subsequently decreases to values between 1 and 3. On the contrary, for a stuck fermentation the fructose/glucose ratio tends to reach a maximum value that remains constant with time (Esti et al., 2003). In the course of the process, the F/G was determined for both fermentation batches (Fig. 2c) and only in the case of the NF strain was an 'anomalous' profile observed, ascribable to a sluggish fermentation.

The profiles of ethanol production, for both batches, are very similar up to $200 \mathrm{~h}$; however, after this period the ethanol concentrations differ according to the total amount of sugar consumed (Fig. 3). The sampling was discontinued when the biosensor data were considered exhaustive in terms of monitoring the fermentation process and its characteristic set of phases.

\subsection{Analysis of must-wine samples using both biosensors and spectrophotometric kits}

In order to verify the reliability of the electrochemical biosensors developed here, spectrophotometric kits for glucose/fructose and ethanol were used to perform analyses in parallel with biosensor measurements. The results from 23 must-wine samples (collected during the ALFs), reported in Fig. 4, showing correlations $\left(r^{2}\right)$ of $0.996,0.993$ and 0.995 for glucose, fructose and ethanol, respectively. These data demonstrate that these devices are reliable and suitable for on site monitoring, and thus show great promise for more effective monitoring of alcoholic fermentations in winery.

\section{Conclusions}

Amperometric biosensors based on screen-printed electrodes were developed for the detection of glucose, fructose and ethanol and then applied in monitoring laboratory micro-ALFs, induced using two different strains of $S$. cerevisiae, that differed in their fructophilic character.

Fermentation profiles, obtained by analysing samples of mustwine at different time intervals, showed that the biosensors allowed to characterise the typical fermentation phases and to highlight the differences in metabolic behaviour of the two strains. Moreover, the experimental data from the biosensors were in good agreement with spectrophotometric analyses, demonstrating that the biosensor devices are suitable for following and managing alcoholic fermentation at real production sites.

\section{References}

Berthels, N. J., Cordero Otero, R. R., Bauer, F. F., Pretorius, I., \& Thevelein, J. M. S (2008). Correlation between glucose/fructose discrepancy and hexokinase kinetic properties in different Saccharomyces cerevisiae wine yeast strains. Applied Microbiology and Biotechnology, 77, 1083-1091.

Berthels, N. J., Cordero Otero, R. R., Bauer, F. F., Thevelein, J. M., \& Pretorius, I. S. (2004). Discrepancy in glucose and fructose utilisation during fermentation by Saccharomyces cerevisiae wine yeast strains. FEMS Yeast Research, 4, 683-689.

Bisson, L. F., \& Butzke, C. E. (2000). Diagnosis and rectification of stuck and sluggish fermentations. American Journal of Enology and Viticulture, 51, 168-177.

Bisson, L. F. (1999). Stuck and sluggish fermentations. American Journal of Enology and Viticulture, 50, 107-119.

Boujtita, M., Hart, J. P., \& Pittson, R. (2000). Development of a disposable ethanol biosensor based on a chemically modified screen-printed electrode coated with alcohol oxidase for the analysis of beer. Biosensors and Bioelectronics, 15 257-263.

Cagnini, A., Palchetti, I., Lionti, I., Mascini, M., \& Turner, A. P. F. (1995). Disposable ruthenised screen printed biosensors for pesticides monitoring. Sensors and Actuators B, 24-25, 85-95.

Curulli, A., Carelli, I., Trischitta, O., \& Palleschi, G. (1997). Enzyme electrode probes obtained by electropolymerization of monomers with PMS and selected dehydrogenase enzymes. Talanta, 44, 1659-1669.

Esti, M., Volpe, G., Compagnone, D., Mariotti, G., Moscone, D., \& Palleschi, G. (2003) Monitoring alcoholic fermentation of red wine by electrochemical biosensors. American Journal of Enology and Viticulture, 54, 39-45.

Goriushkina, T. B., Soldatkin, A. P., \& Dzyadevych, S. V. (2009). Application of amperometric biosensors for analysis of ethanol, glucose and lactate in wine. Journal of Agricultural and Food Chemistry, 57, 6528-6535.

Niculescu, M., Mieliauskiene, R., Laurinavicius, V., \& Csöregi, E. (2003). Simultaneous detection of ethanol, glucose and glycerol in wines using pyrroloquinoline quinone-dependent dehydrogenases based biosensors. Food Chemistry, 82, 481-489.

Patel, N. G., Meier, S., Cammann, K., \& Chemnitius, G. C. (2001). Screen-printed biosensors using different alcohol oxidases. Sensors and Actuators B, 75, 101-110.

Ricci, F., Amine, A., Palleschi, G., \& Moscone, D. (2003). Prussian Blue based screen printed biosensors with improved characteristics of long-term lifetime and $\mathrm{pH}$ stability. Biosensors and Bioelectronics, 18, 135-174.

Ricci, F., Moscone, D., Tuta, C. S., Palleschi, G., Amine, A., Poscia, A., et al. (2005) Novel planar glucose biosensors for continuous monitoring use. Biosensors and Bioelectronics, 20, 1993-2000.

Santos, J., Sousa, M. J., Cardoso, H., Inàcio, J., Silva, S., Spencer-Martins, I., et al (2008). Ethanol tolerance of sugar transport, and the rectification of stuck wine fermentations. Microbiology, 154, 422-430.

Trivedi, U. B., Lakshminarayana, D., Kothari, I. L., Patel, P. B., \& Panchal, C. J. (2009). Amperometric fructose biosensor based on fructose dehydrogenase enzyme. Sensors and Actuators B, 136, 45-51. 